\title{
ANÁLISE DE ACESSIBILIDADE EM AMBIENTE DE ESTUDO: O POLO CEDERJ NITERÓI
}

\section{ANALYSIS OF ACCESSIBILITY IN A STUDY AMBIENCE: THE CEDERJ NITERÓI POLO.}

\author{
Luciana Tavares Perdigão ${ }^{1}$, Esp. (Autores) \\ Neuza Rejane Wille Lima², PhD. \\ Sergio Rodrigues Bahia ${ }^{3}, \mathrm{PhD}$. \\ (1) Fundação Cecierj e Universidade Federal Fluminense (Instituição) \\ e-mail: lucianaperdigao@id.uff.br \\ (2) Coordenadora do CMPDI / Universidade Federal Fluminense \\ e-mail: rejane lima@id.uff.br \\ (3) Departamento de Urbanismo / Universidade Federal Fluminense \\ e-mail: sergiorodriguesbahia@gmail.com /srbahia@id.uff.br
}

Palavras-chave em português (EAD, Acessibilidade, Desenho Universal)

O Consórcio Cederj permite o acesso ao ensino superior a distância através da plataforma Moodle com o apoio dos polos de tutoria presencial. O objetivo deste estudo foi analisar as condições de acessibilidade física do polo de Niterói como base na norma ABNT NBR 9050/2015. Espera-se que esse estudo possa ser ampliado para os demais polos do Consórcio.

\section{Key-words in English (e-learning, acessibility, Universal Design)}

The Cederj Consortium allows access to e-learning higher education through the Moodle platform with the support of the classroom tutoring centers. The objective of this study was to analyze the physical accessibility conditions of the Niterói polo as base in the ABNT NBR 9050/2015 standard. It is hoped that this study could be extended to the other poles of the Consortium.

\section{Introdução}

A Educação a Distância - EaD é uma modalidade de ensino que tem ganhado espaço no cenário educacional do Brasil, rompendo barreiras geográficas, sociais e culturais, provendo a formação sistêmica do conhecimento. Possui uma relevância social ao permitir o acesso amplo à educação superior promovendo a inclusão (SILVA JÚNIOR et. al., 2015). 


\section{$16^{\circ}$ \\ ERGODESIGN USIHC CINAHPA}

O presente estudo foi realizado no Consórcio Cederj (Centro de Educação Superior a Distância do Estado do Rio de Janeiro) que é formado por sete instituições públicas de ensino superior: CEFET, UENF, UERJ, UFF, UFRJ, UFRRJ e UNIRIO. O objetivo do consórcio é levar educação superior, gratuita e de qualidade a todo o Estado do Rio de Janeiro, e atualmente conta com mais de 45 mil alunos matriculados em seus 15 cursos de graduação a distância. A partir da perspectiva de interiorização, nos últimos anos vêm crescendo o número de alunos com necessidades educacionais especiais participando do sistema, o que vem demandando no Consórcio a necessidade de estruturar metodologias para acompanhamento destes alunos. De acordo com o levantamento da diretoria de polos da instituição, 72 alunos com algum tipo de deficiência foram matriculados nos cursos superiores do Cederj no segundo semestre de 2016.

Com posse das informações acima detalhadas, foram levantadas as seguintes questões: os polos Cederj estão preparados fisicamente para receber um aluno com necessidade educacional especial? Quais são os requisitos mínimos para o atendimento adequado a esse aluno? Como objeto de estudo foi analisado o polo Cederj de Niterói, inicialmente apenas por conveniência de acesso da pesquisadora mas que ao longo do estudo foi descoberto que se trata de uma escola que é referência em inclusão na rede municipal de Niterói.

Este estudo faz parte de um trabalho de conclusão da disciplina Análise das Condições de Acessibilidade nos Ambientes de Ensino e Trabalho do Curso de Mestrado Profissional em Diversidade e Inclusão - CMPDI da Universidade Federal Fluminense - UFF.

\section{Educação a distância}

De acordo com Maia \& Mattar (2007), a EaD (Educação a Distância) depende do envolvimento de diversos sujeitos como alunos, professores, instituições de ensino, empresas e governo, para o pleno funcionamento. Segundo o Anuário Brasileiro Estatístico de Educação Aberta e a $16^{\circ}$ Ergodesign - Congresso Internacional de Ergonomia e Usabilidade de Interfaces Humano Tecnológica: Produto, Informações Ambientes Construídos e Transporte

$16^{\circ}$ USIHC - Congresso Internacional de Ergonomia e Usabilidade de Interfaces Humano Computador

CINAHPA | 2017 - Congresso Internacional de Ambientes Hipermídia para Aprendizagem.

Distância a crescente evolução da EaD no Brasil tanto no aspecto quantitativo como qualitativo é respaldado por uma legislação bem estabelecida (ABRAEAD, 2008). O respaldo legal da EaD no Brasil teve início com a Lei de Diretrizes e Bases da Educação (LDB) - Lei 9.394, de 20 de dezembro de 1996. Mas foi somente em 2005 que a Educação a distância foi conceituada como modalidade educacional através do Decreto $\mathrm{n}^{\circ}$ 5.622:
"Art. $1^{\circ}$ : Para os fins deste Decreto, caracteriza a Educação a Distância como modalidade educacional na qual a mediação didático-pedagógica nos processos de ensino e aprendizagem ocorre com a utilização de meios e tecnologias de informação e comunicação, com estudantes e professores desenvolvendo atividades educativas em lugares ou tempos diversos" (Brasil, 2005)

Nesse intervalo foi criada a Fundação Cecierj Fundação Centro de Ciências e Educação Superior a Distância do Estado do Rio de Janeiro - através da lei complementar $\mathrm{N}^{\circ} 103$ de 18 de março de 2002 e que tem como um dos objetivos sociais:

\footnotetext{
“Art. $2^{\circ}$ - I: oferecer educação superior gratuita e de qualidade, na modalidade a distância, para o conjunto da comunidade fluminense." (Rio de Janeiro, 2002)
}

A Fundação Cecierj tem como missão criar mecanismos que incentivem e promovam a formação continuada de profissionais da educação para que participem da sociedade do conhecimento, contribuindo para a prática da coesão social, da cidadania ativa, do diálogo intercultural e da igualdade de oportunidades (Rio de Janeiro, 2010). A instituição está diretamente ligada à perspectiva de acessibilidade e inclusão: através da portaria 183 publicada no Diário Oficial de 16 de agosto de 2011, foi criada a Comissão de Atendimento ao Aluno com Necessidades Educacionais Especiais (NEE) que institui um modelo de trabalho em que garante carga horária de tutoria presencial para apoio aos alunos com necessidades educacionais. A partir das informações acima detalhadas foi levantada a primeira questão de pesquisa, sobre a capacidade do polo de receber o aluno NEE.

Realização:




\section{$16^{\circ}$ \\ ERGODESIGN USIHC CINAHPA}

$16^{\circ}$ Ergodesign - Congresso Internacional de Ergonomia e Usabilidade de Interfaces Humano Tecnológica: Produto, Informações Ambientes Construídos e Transporte

$16^{\circ}$ USIHC - Congresso Internacional de Ergonomia e Usabilidade de Interfaces Humano Computador

CINAHPA | 2017 - Congresso Internacional de Ambientes Hipermídia para Aprendizagem.

\section{Polo de Apoio Presencial e a inclusão}

O polo de apoio presencial é o local, devidamente credenciado pelo Ministério da Educação - MEC, próprio para o desenvolvimento descentralizado de atividades pedagógicas e administrativas relativas aos cursos e programas ofertados a distância.

(Brasil, 2007)

De acordo com o Regimento Interno da Fundação Cecierj (Rio de Janeiro, 2010), a tutoria presencial será realizada nos polos regionais, quando os alunos contarão com sessões semanais de encontro presencial para disciplinas iniciais dos cursos de graduação, ou com outra periodicidade proposta pelas coordenações, em função das especificidades de cada curso. A localização dos polos depende de convênios específicos firmados com as prefeituras municipais ou outras instituições.

O local escolhido para realização deste estudo foi o Polo de Niterói, inicialmente apenas por conveniência de acesso da pesquisadora, localizado na Escola Municipal Paulo Freire, em Niterói - RJ. Ao longo da pesquisa foi descoberto que esta escola é referência em educação inclusiva no município. (ALMEIDA, 2013)

\section{Análise do Espaço}

A metodologia de pesquisa foi um trabalho de campo onde foram realizadas entrevistas de sondagens de opinião (MINAYO, 2007) com a diretora e o tutor coordenador do polo; registros fotográficos e de medição e análise dos dados coletados em relação a acessibilidade física do espaço com base na-norma da ABNT 9050 (2015) e nos Princípios do Desenho Universal (MPSP, 2010). O objeto de estudo foi a sala $9 \mathrm{C}$ no terceiro andar, o mobiliário e a distribuição espacial, além do acesso até esse ambiente de tutoria.

O primeiro registro foi da entrada do edifício até o elevador: é uma rota acessível com uma rampa em dois níveis e piso liso. De acordo com a ABNT (2015), o conceito de rota acessível é:

\begin{abstract}
"trajeto contínuo, desobstruído e sinalizado, que conecte os ambientes externos ou internos de espaços e edificações, e que possa ser utilizado de forma autônoma e segura por todas as pessoas, inclusive aquelas com deficiência e mobilidade reduzida. A rota acessível pode incorporar estacionamentos, calçadas rebaixadas, faixas de travessia de pedestres, pisos, corredores, escadas e rampas, entre outros"
\end{abstract}

Nesse caso, atende ao princípio do uso equitativo do desenho universal, onde o acesso ao edifício se dá através de rampas com corrimãos e guardacorpo. O problema registrado foi a falta de um dos corrimãos da rampa que encontrava-se danificado. Também não foram encontrados pisos táteis em nenhum dos ambientes da escola. No caso específico da rampa, haveria a necessidade de sinalizar, com o piso de alerta, a área de mudança de declividades.

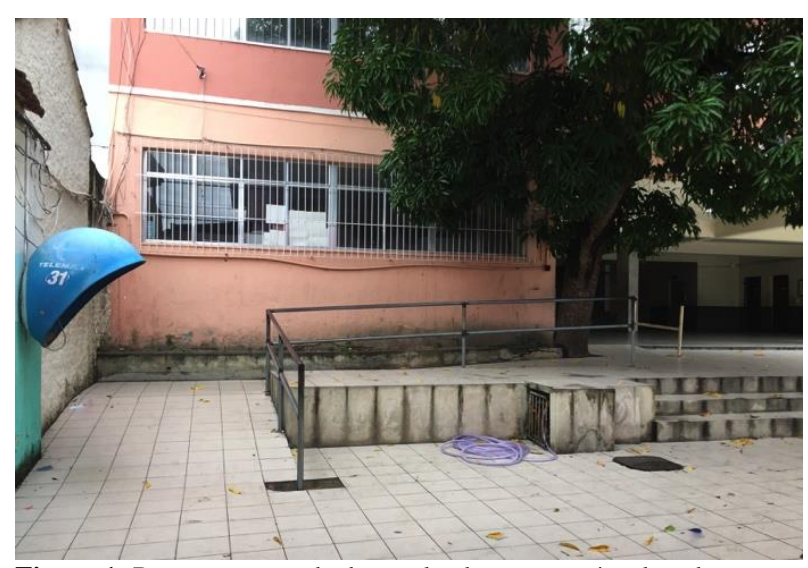

Figura 1: Rampa na entrada da escola, de acesso até o elevador. FONTE: Da autora.

O segundo registro foi da porta do elevador, que atende a largura mínima $(0,80 \mathrm{~m})$ de vão de porta, havendo um desnível superior a $0,02 \mathrm{~m}$ entre o nível do piso do elevador e o corredor, onde foi adotada a construção de rampa.

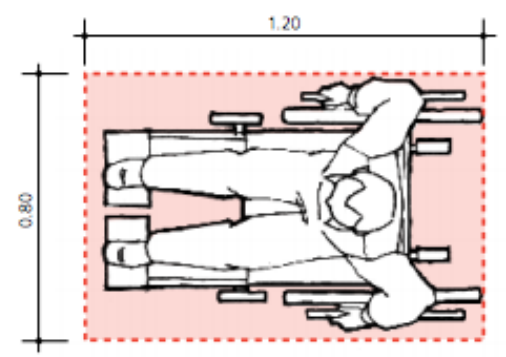

Figura 2A: Largura mínima para vãos. Fonte: MPSP, 2010.
Realização:
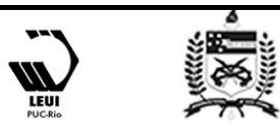

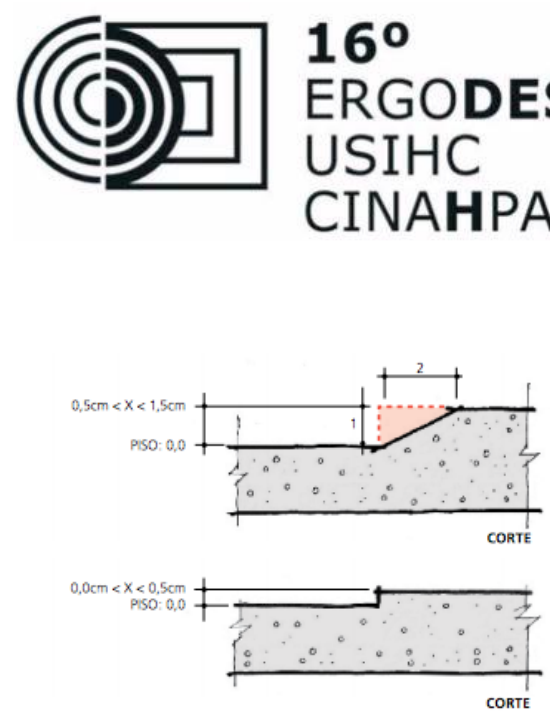

Figura 2B: Desníveis mínimos. Fonte: MPSP, 2010.

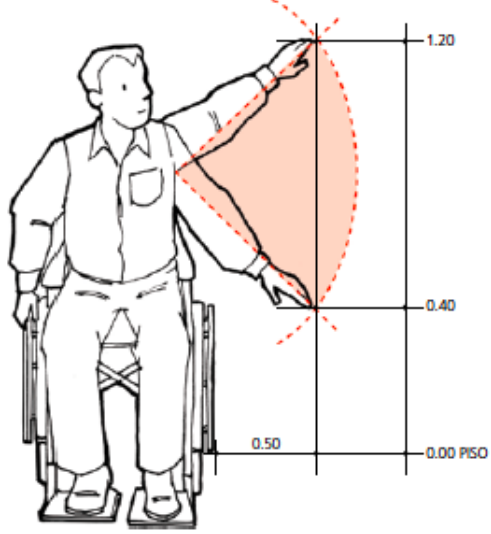

Figura 2C: Alcance dos comandos. Fonte: MPSP, 2010.
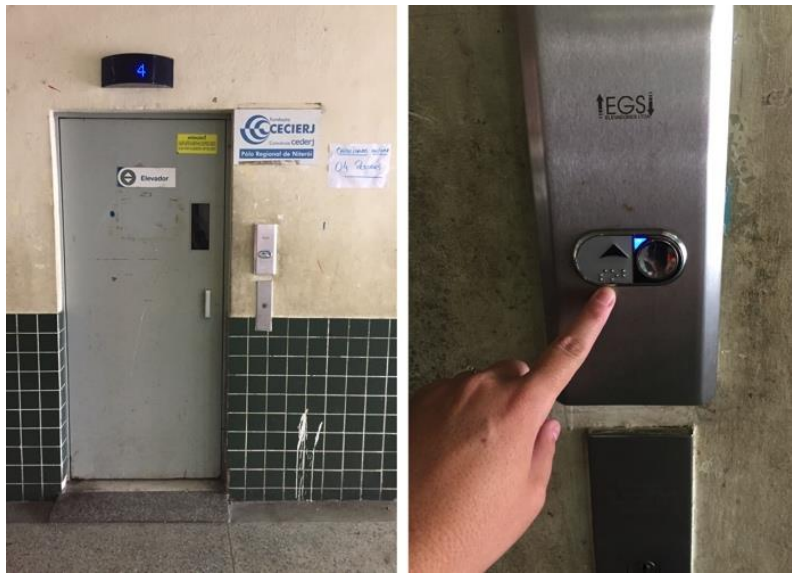

Figura 2D: Porta do elevador com tratamento de desnível e detalhe do botão de acesso em braille. Fonte: Da autora.

O terceiro registro foi o levantamento completo da estrutura física da sala 9C. Para um melhor entendimento dos registros foi realizado um croqui da planta baixa da sala com interferências de registros fotográficos (Ver ampliado no Anexo 1). $16^{\circ}$ Ergodesign - Congresso Internacional de Ergonomia e Usabilidade de Interfaces Humano Tecnológica: Produto, Informações Ambientes Construídos e Transporte

$16^{\circ}$ USIHC - Congresso Internacional de Ergonomia e Usabilidade de Interfaces Humano Computador

CINAHPA | 2017 - Congresso Internacional de Ambientes Hipermídia para Aprendizagem.

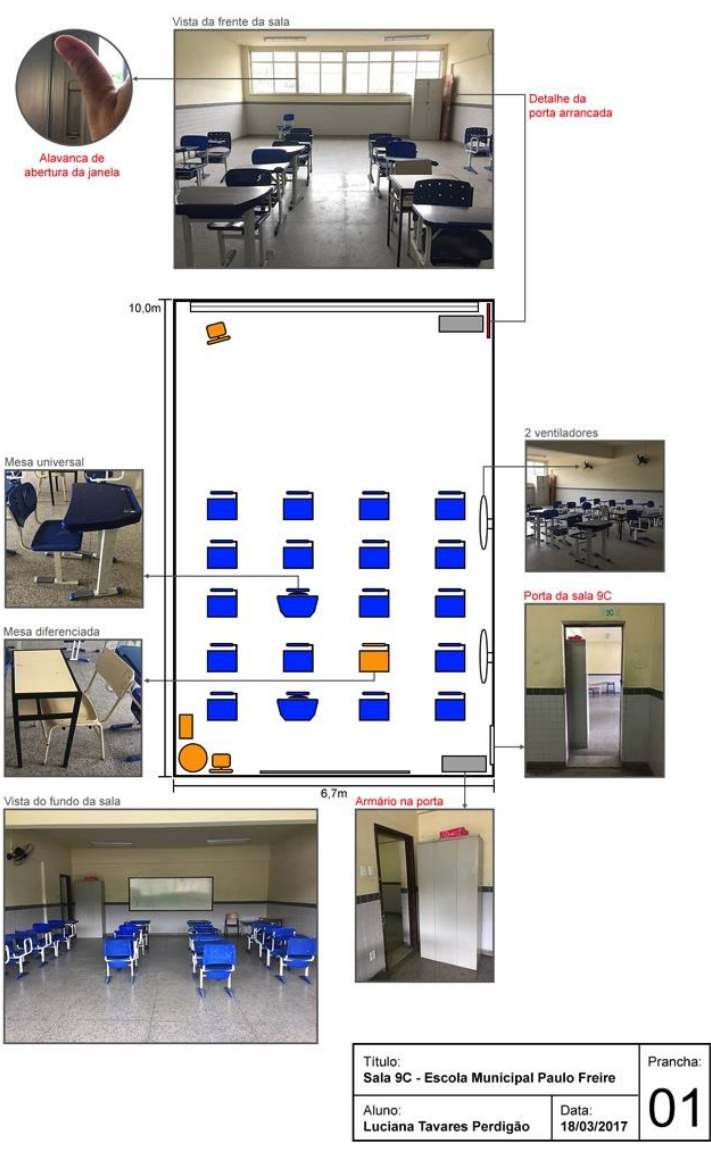

Figura 3: Croqui da Sala 9C. Fonte: Da autora.

Foram observados os seguintes pontos:

1. A porta de entrada da sala, além de ter sido retirada, está com o vão de acesso parcialmente obstruído por um armário indevidamente posicionado à sua frente.

2. A sala possui duas estações de estudo acessíveis, mas poderiam ser melhor localizadas no espaço da sala

3. Os demais pontos como ventilação, abertura de janelas e interruptores foram considerados como de acesso ao tutor e não ao aluno NEE por isso não foram considerados neste estudo. Sob a ótica do Desenho Universal, seriam esses pontos falhos na análise de elementos de comandos existentes (interruptores, puxadores/fechos de janelas etc).

Conforme citado anteriormente o vão da porta não 


\section{$16^{\circ}$ \\ ERGODESIGN USIHC CINAHPA}

$16^{\circ}$ Ergodesign - Congresso Internacional de Ergonomia e Usabilidade de Interfaces Humano Tecnológica: Produto, Informações Ambientes Construídos e Transporte

$16^{\circ}$ USIHC - Congresso Internacional de Ergonomia e Usabilidade de Interfaces Humano Computador

CINAHPA | 2017 - Congresso Internacional de Ambientes Hipermídia para Aprendizagem. está de acordo com as normas de acessibilidade. Já as mesas ou superfícies de trabalho acessíveis, de acordo com a NBR 9050/2015, devem possuir tampo com largura mínima de $0,90 \mathrm{~m}$ e altura entre $0,75 \mathrm{~m}$ e $0,85 \mathrm{~m}$ do piso acabado, assegurando-se largura livre mínima sob a superfície de $0,80 \mathrm{~m}$. Logo as estações de estudo encontradas na sala estão de acordo com a norma.

\section{Conclusões}

Com algumas modificações na distribuição do mobiliário no espaço, como a retirada do armário da frente do vão da porta e o reposicionamento das duas estações de trabalho acessíveis, a sala 9C se tornará um espaço de atendimento acessível no Polo Cederj Niterói. Busca-se como pesquisa futura coletar as opiniões de funcionários, professores e alunos (especialmente os alunos NEE) que frequentam o polo e analisar os demais espaços para criação de um checklist colaborativo para diagnóstico e adequações dos demais polos do Consórcio Cederj, reforçando, assim, a necessidade de envolvimento de todos os usuários da escola na construção de um espaço de fato acessível a todos.

\section{Referências Bibliográficas}

ABNT, Associação Brasileira de Normas Técnicas. Norma NBR 9050, Acessibilidade a Edificações, Mobiliário, Espaços e Equipamentos Urbanos. Rio de Janeiro, 2015.

\footnotetext{
ALMEIDA, E. Atendimento educacional especializado e educação inclusiva: quais as experiências das salas de recursos multifuncionais nas escolas públicas de Niterói/RJ? - 2013. Disponível em http://www.oneesp.ufscar.br/atendimentoeducacional-especializado-e-educacao-inclusivaquais-as-experiencias-das-salas-de-recursosmultifuncionais-nas-escolas-publicas-de-niteroi-
}

rj.pdf Acesso em 20 mar. 2017.

BRASIL. Decreto ${ }^{\circ} 5.622$, de 19 de dezembro de 2005. Disponível em:

http://portal.mec.gov.br/seed/arquivos/pdf/dec_562 2.pdf. Acesso em 16 mar. 2017.

BRASIL. Instituto Nacional de Estudos e Pesquisas Educacionais Anísio Teixeira. Legislação e Documentos. Disponível em: http://download.inep.gov.br/download/superior/20 04/censosuperior/Resumo_tecnicoCenso 2004.pdf . Acesso em 16 mar. 2017.

BRASIL. Ministério da Educação. Legislação da Educação a Distância. Disponível em: http://portal.mec.gov.br/seed/arquivos/pdf/legislaca o/refead1.pdf. Acesso em 20 mar. 2017.

MAIA, C.; J. MATTAR. ABC da EaD: a Educação a Distância hoje. 1. ed. São Paulo: Pearson. 2007.

MINAYO, M.C.S. (Org.). Pesquisa Social: teoria, método e criatividade. 26.ed. Petrópolis, RJ: Vozes, 2007.

RIO DE JANEIRO, Fundação Cecierj. Regimento Interno da Fundação Centro de Ciências e Educação Superior a Distância do Estado do Rio de Janeiro. 2010. Disponível em http://cederj.edu.br/fundacao/regimento-interno/ . Acesso em 15 mar. 2017.

SÃO PAULO, Governo do Estado. Desenho Universal - Habitação de Interesse Social. Disponível em http://www.mpsp.mp.br/portal/page/portal/Cartilha s/manual-desenho-universal.pdf . Acesso em 17 mar. 2017.

SILVA JÚNIOR J. B. et. al. Educação a distância: desafio e perspectivas. Educação Pública: Rio de Janeiro, 2015. Disponível em http://educacaopublica.cederj.edu.br/revista/artigos leducacao-a-distancia-desafio-e-perspectivas . Acesso em 17. Mar. 2017. 


\section{$16^{\circ}$ \\ ERGODESIGN USIHC CINAHPA}

$16^{\circ}$ Ergodesign - Congresso Internacional de Ergonomia e Usabilidade de Interfaces Humano Tecnológica: Produto, Informações Ambientes Construídos e Transporte

$16^{\circ}$ USIHC - Congresso Internacional de Ergonomia e Usabilidade de Interfaces Humano Computador

CINAHPA | 2017 - Congresso Internacional de Ambientes Hipermídia para Aprendizagem.

ANEXO 1 - Croqui da Sala 9C: Pólo Cederj Niterói - Escola Municipal Paulo Freire

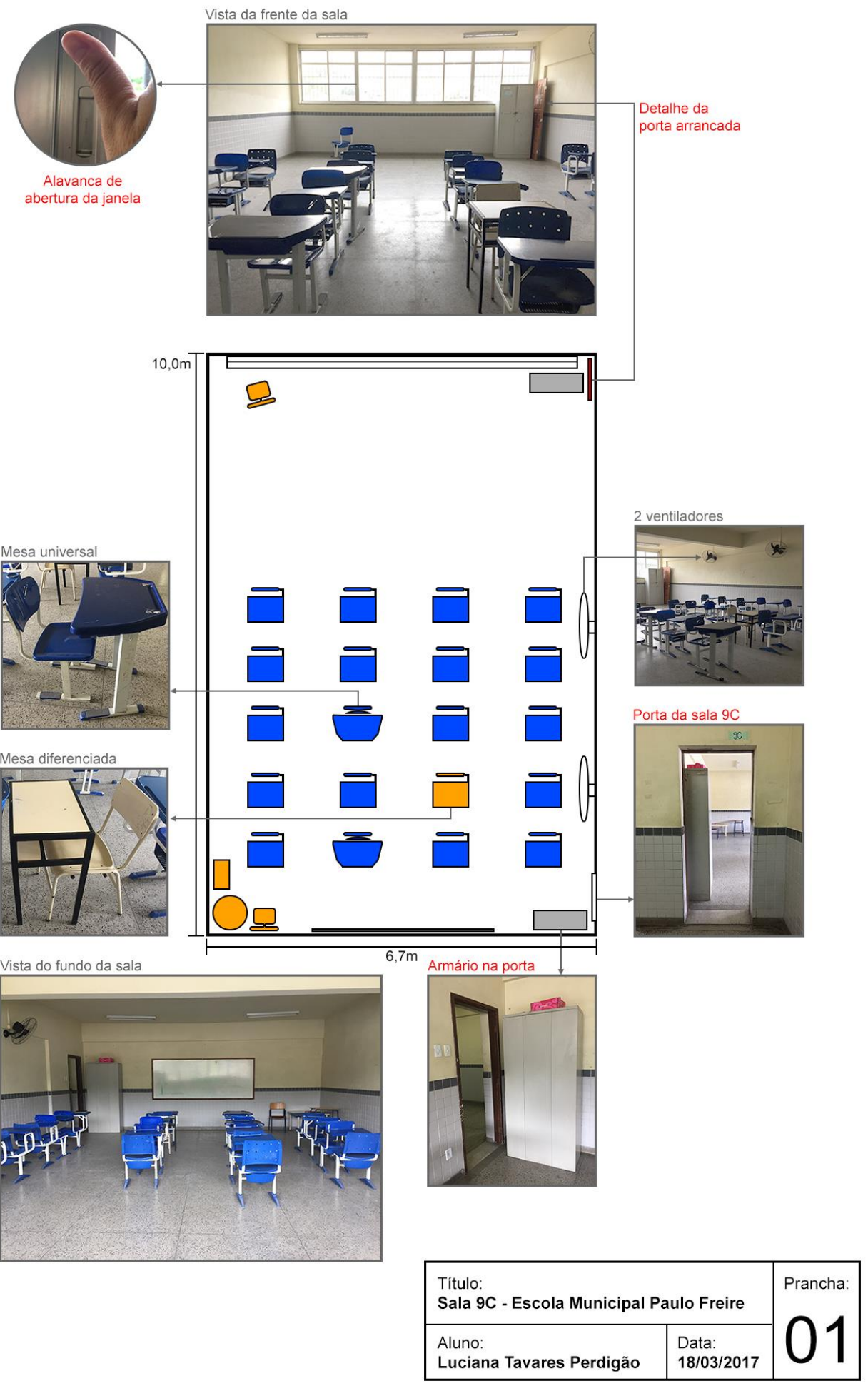

